\title{
40 ANOS DE INDEPENDÊNCIA. UMA REFLEXÃO EM TORNO DA CONDIÇÃO DA MULHER ANGOLANA
}

\author{
Ermelinda Liberato \\ Universidade Agostinho Neto, Luanda, Angola
}

Resumo: A comemoração dos 40 anos de independência de Angola constitui o ponto de partida para fazermos um balanço sobre a condição e a posição da mulher naquele país ao longo desse período. Por se tratar de um período longo, marcado por inúmeros acontecimentos que de uma forma ou de outra moldaram o país, dividimos a nossa análise em três momentos distintos: o primeiro corresponde ao período pós-independência, caracterizado pela luta das mulheres pelo reconhecimento da sua condição e pela sua afirmação; o segundo compreende o período pós-guerra (2002-2015), caracterizado por um crescimento económico significativo, de expectativas, sonhos e de esperança na melhoria da sua condição e posição na sociedade. O terceiro momento, mais atual, corresponde à análise da realidade, numa confrontação entre os dados recolhidos e a realidade observada que nos leva a concluir que as condições de vida da mulher angolana, e em particular a sua posição na sociedade é, de longe, muito mais complexa do que aquela que os documentos nos transmitem.

Palavras-chave: Mulher; Angola; Independência.

\section{Introdução}

Quando Agostinho Neto proclamou, a 11 de novembro de 1975, a independência da República Popular de Angola (MI, 1975), pondo fim a quase 500 anos de dominação colonial portuguesa, definiu, nessa mesma noite, as bases sob as quais se iria assentar a mais jovem nação. Com destaque para a condição da mulher angolana:

A República Popular de Angola, sob a orientação justa do MPLA [Movimento Popular de Libertação de Angola] estimulará o processo de emancipação da mulher angolana, direito conquistado através da sua participação na luta de libertação e na produção para a resistência generalizada do nosso povo (Ml, 1975, p. 16). 
Ficou assim definido que a igualdade e equidade entre todos os cidadãos, particularmente no que toca à condição da mulher angolana, colocada durante séculos, numa posição de subordinação em relação ao homem (Henda DUCADOS, 2000) constituiria o pilar desse empreendimento. Desde a data da proclamação da independência até o presente, o país tem enfrentado inúmeros desafios e constrangimentos, ultrapassando barreiras, fortalecendo-se com cada experiência e, sobretudo, construindo a sua realidade. De então para cá 40 anos se passaram, que se traduzem essencialmente em 40 anos de luta em todas as dimensões - social, civil, política, económica, militar, cultural - 40 anos de ideologias, de sonhos, de desejos, de expectativas; porém, igualmente, de desilusões, de frustrações, de cansaço, de desespero. Em 40 anos, gerações de angolanos nasceram no turbilhão que foi o período pós-independência, enfrentaram uma longa e devastadora guerra civil', deram início à caminhada para a construção e à manutenção da paz e reconciliação nacional. Concordamos que 40 anos para um país ainda é muito pouco. Contudo, há que fazer uma reflexão dessa trajetória de modo que possamos entender de onde viemos, onde estamos e que caminho seguiremos no futuro.

Desse modo, estruturamos a nossa apresentação em três momentos distintos. Primeiramente, traçamos, de modo geral, o percurso de luta da mulher angolana pelo reconhecimento do seu papel na sociedade e pela conquista do direito de igualdade de tratamento perante uma ideologia fortemente implantada, de posição subalterna em relação ao sexo masculino. Trata-se de um período de euforia, de sonhos e de expectativas em relação ao futuro. Em seguida, focamos a nossa análise para os acontecimentos mais recentes, refletindo sobre a posição da mulher angolana no período correspondente a 2002-2015, caracterizado pelo fim da violência armada e pela expectativa de reconstrução do país e, sobretudo, de reconciliação nacional. Os dados recolhidos mostram-nos uma realidade mais animadora, em comparação com o período anterior, expectando-se, desse modo, uma melhoria das condições de vida dos angolanos em geral, e da condição da mulher em particular. Num terceiro momento, confrontamos esses dados com a realidade que observamos, ou seja, tentamos analisá-los com o quotidiano que os angolanos no geral, e as mulheres em particular, enfrentam. Esse confronto, leva-nos, num momento inicial, a questionar tanto a validade desses mesmos números quanto a da nossa observação, na medida em que não encontramos correspondência entre os mesmos. Ou seja, apesar de os dados recolhidos para o período mais recente (2002-2015) serem mais otimistas e nos revelarem uma melhoria das condições de vida dos angolanos no geral, a realidade observada mostra-nos uma população a viver maioritariamente em condições de pobreza, com dificuldades de acesso às condições básicas e vivendo em condições precárias. A fragilidade dessas informações leva-nos a concluir que as condições de vida da mulher angolana, e em particular a sua posição na sociedade, é, de longe, muito mais complexa do que aquela que os documentos nos transmitem.

\section{Metodologia}

O desenvolvimento de qualquer investigação que tenha como objeto de estudo Angola apresenta-se, à partida, como um desafio em todas as dimensões, seja em termos de pesquisa bibliográfica, seja em termos de trabalho de campo.

O facto de o país praticamente não ter realizado estudos de qualquer natureza desde a independência (Inge TUEDTEN, 1997, p. 8), bem como de não ter conseguido preservar grande parte do material de arquivo já existente devido não só aos efeitos da

${ }^{1}$ A guerra civil angolana durou aproximadamente 27 anos. 
guerra civil como também de falta de pessoal qualificado para o efeito, fazem como que Angola apresente um problema muito sério de escassez de dados de toda a ordem, particularmente estatísticos (Luís VINYALS, 2002; PNUD, 2002; WEF, 2012), fazendo com que a informação disponível e credível seja bastante limitada, motivo pelo qual o país seja constantemente retirado de relatórios internacionais (WEF, 2012; WEF, 2013). Uma forma de ultrapassarmos essa limitação prende-se com a consulta de documentos produzidos mais recentemente pelos principais organismos internacionais, nomeadamente, o Fundo Monetário Internacional (FMI), o Banco Mundial (BM) ou o Programa das Nações Unidas para o Desenvolvimento (PNUD), pois, apesar da fragilidade dos mesmos, uma vez que, na maioria dos casos, os estudos não abrangem todo o país e não refletem a sua realidade, são os únicos dados de que dispomos.

Uma vez que "a escassez de dados impõe-se como uma das dificuldades maiores para uma análise mais circunstanciada e fundamentada dos problemas que afetam as mulheres" (Maria Idalina VALENTE, 2001, p. 4), optamos ainda por conjugar essa análise com a informação recolhida no terreno, utilizando para o efeito a técnica da observação direta, bem como a realização de entrevistas conduzidas no âmbito do projeto de investigação "O Antes, o Agora e o Depois: Angola 40 anos", que está a ser desenvolvido pela autora e cujo objetivo passa precisamente por fazer uma análise destes 40 anos de independência do país, de modo que a informação aqui apresentada esteja assente essencialmente em constatações e indagações da própria.

De realçar ainda que o facto de a investigadora ser angolana, residir em Angola e estar a analisar aquele que também foi parte do seu percurso enquanto cidadã daquele país, apresenta-se como o principal constrangimento a ser ultrapassado, pois, o que a princípio poderia ser vantajoso - posto estar familiarizada com a situação, identificação dos diferentes acontecimentos, conhecimento da história e do percurso do país, domínio sobre o terreno - revelou-se igualmente desvantajoso, na medida em que foi difícil manter o distanciamento entre a ciência e o senso comum, ou seja, entre a cidadã e a investigadora. Por mais que se tente ser imparcial e se olhe para a ciência com objetividade, manter a distância entre aquilo que somos (cidadãos), de onde viemos (Angola), e do próprio meio social onde nos inserimos e nos movimentamos (Luanda) apresenta-se como um desafio difícil de ultrapassar.

\section{O início de um sonho}

O debate em torno do papel da mulher na sociedade, bem como a questão da igualdade entre os géneros nunca foi tão intenso como aquele que temos registado nos últimos anos (Libertat JIMENEZ; Ermelinda LIBERATO, 2015). No caso do continente africano, onde Angola se insere, essa questão assume uma dimensão ainda maior, pois é apontada como um dos maiores entraves para a melhoria das condições de vida no continente e, consequentemente, para o seu desenvolvimento.

Ao longo dos anos, a mulher angolana foi relegada para uma posição inferior àquela que era dada ao homem, isso apesar de Afonso Mendes ter referido, em 1958, que é na mulher africana, e não no homem, que assenta toda a base económica (Afonso MENDES, 1958). Por outro lado, não podemos esquecer do papel e do peso que os valores culturais e a tradição ainda têm na sociedade angolana, tipicamente africana, no qual a mulher é relegada para a condição de subalternização ao homem, e o seu espaço de afirmação é reduzido (Eugénio Alves da SILVA, 2011).

Durante o período da luta armada de libertação nacional contra o poder colonial (1961-1974), a emancipação da mulher foi considerada essencial para o processo 
revolucionário e um "pré-requisito para o desenvolvimento nacional" (Marga HOLNESS, 1983, p. 125). O MPLA não se identificava apenas como mais um movimento nacionalista, mas como um movimento comprometido com a transformação total das relações sociais baseadas no princípio da igualdade de acesso aos meios de produção, o que fez com que adotasse "uma estratégia de combate a seguir para restituir à mulher o lugar que de direito Ihe cab[ia] na nova sociedade que revolucionariamente esta[va] a construir" (José FORTUNATO, 1977, p. 91).

Foi nesse contexto consciente de construção de uma "nova Angola"2 que o status das mulheres angolanas foi marcadamente alterado, ao assumirem uma variedade de funções, incluindo as de guerrilheiras e de delegadas políticas. A ideologia do movimento, e depois como partido governante, tornou-se crucial para o progresso das mulheres angolanas no período pós-colonial, ao receberem um significativo encorajamento da parte do partido para assumirem mais responsabilidades e empreenderem novas tarefas. Elas se tornaram enfermeiras (e chefes de hospitais), comissárias políticas, professoras e diretoras de escolas, jornalistas, engenheiras, militares, corpo da polícia (Stephanie URDANG, 1984).

Um exemplo desse esforço é o abandono oficial dos antigos termos senhor (Sr.) e senhora (Sra.) em favor de camaradas para ambos os sexos. Assim, as mulheres e os homens eram iguais e recebiam o mesmo tratamento. Por outro lado, a Constituição da República Popular de Angola (RPA) também estabeleceu

o direito ao trabalho, à educação e à saúde, e à proteção e escolaridade completa para crianças, garantindo também a igualdade de remuneração por igual trabalho, férias pagas e acesso gratuito a todas as ocupações, como algumas das medidas para garantir o pleno desenvolvimento das mulheres na sociedade (OMA, 1985, p. 2).

Ao contrário do que aconteceu no Zaire (atual República Democrática do Congo) com a política de zairização ${ }^{3}$ de Mobutu, em Angola o movimento tem apoiado as organizações de mulheres, bem como dado espaço para a realização das suas atividades. A responsabilidade por esse departamento foi atribuída à Organização das Mulheres Angolanas (OMA), incorporada na estrutura do MPLA e projetada para defender os interesses das mulheres. A organização albergou na sua estrutura todas as mulheres angolanas, independentemente da sua condição, quer fossem camponesas, funcionárias públicas, intelectuais etc., sendo que "durante os primeiros anos de independência, a atividade principal da OMA foi de apoio aos diferentes programas de governo" (HOLNESS, 1983, p. 126) tornando-se numa das mais poderosas organizações de massa do partido. A presença dos principais líderes do movimento em atividades da OMA, como aconteceu durante a realização do seu congresso em 1983, onde o presidente da República marcou presença, é apenas um dos muitos exemplos.

A OMA fez um bom trabalho no que toca à educação das mulheres na ideologia do partido, não só na construção de uma sociedade socialista, mas, o mais importante, na ideia de "trabalhar para a construção de uma nova Angola". E as mulheres engajaram-se nessa luta de tal forma que até o final da década de 1980 estavam presentes em "todos os sectores e em todos os níveis de atividade económica" (Naiole Cohen SANTOS, 2000, p. 27),

\footnotetext{
${ }^{2}$ O sonho de construção de uma "nova Angola" está descrito na primeira constituição da República Popular de Angola, bem como nos discursos do primeiro presidente daquele país, António Agostinho Neto.

${ }_{3}^{3}$ Política implementada por Mobutut Sese Seko, presidente do ex-Zaire (atual República Democrática do Congo (RDC), que consistia no apagamento de todos os vestígios formais do colonialismo, sinónimo de ocidental, defendendo um retorno em pleno às origens, ou seja, à tradição, denominado pelo próprio como "l'authenticité".
} 
alcançando, desse modo, maior independência económica e autonomia em relação ao período colonial. Como exemplo desse esforço de afirmação, até 1984, "297.604 mulheres foram alfabetizadas, incluindo 108.479 domésticas, 105,873 trabalhadoras e 8.644 membros da OMA" (OMA, 1984, p. 31).

A guerra civil foi o maior desafio que as mulheres angolanas enfrentaram no período pós-independência. A partida dos homens para o cumprimento do serviço militar fez com que assumissem a responsabilidade pela segurança e subsistência das suas famílias. No entanto, o seu baixo nível de alfabetização e a "ausência de um sector manufatureiro voltado para a exportação mantiveram a força de trabalho feminino nos sectores informais rurais e urbanos da economia (agrícola, de subsistência e não agrícola)" (UNCTAD, 2013, p. 14), dificultando ainda mais o seu processo de afirmação e, consequentemente, de melhoria da sua posição social, bem como as perspetivas de um futuro melhor, de modo que, quando finalmente as hostilidades cessaram e se alcançou a paz, as expectativas para alterar esse cenário aumentaram.

\section{A falsa esperança}

O término da guerra civil em 2002 abriu caminho para a reconstrução nacional, em todos os aspetos - político, económico, social -, bem como permitiu impulsionar para uma revitalização económica (Manuel Enes FERREIRA; Francisco Rocha GONÇALVES, 2009; HRW, 2010; Alves da ROCHA, 2013), fazendo com que o país se tornasse em uma das economias mundiais que mais cresceu, apresentando um PIB na ordem dos $20,6 \%$ em 2005, $18,6 \%$ em 2006 e aproximadamente 27\% em 2007 (OECD, 2010, p. 40). No entanto, não podemos deixar de realçar que esse crescimento esteve sempre assente num único produto: o petróleo. Entre 1999 e 2008, a "exportação de petróleo em bruto [...] representou em média $91 \%$ das exportações de Angola" (Maciel SANTOS, 2012, p. 32). Tal dependência aumentou para $98 \%$ em 2012 , sendo que também, internamente, $80 \%$ das receitas fiscais públicas provêm do mesmo produto (ADB, 2012, p. 7). Esses dados fazem de Angola o $5^{\circ}$ produtor mundial de petróleo e o $2^{\circ}$ país exportador de petróleo do continente (ROCHA, 2014, p. 12) e, ainda, dá a conhecer a posição bastante vulnerável do país a choques externos.

Esta recuperação económica fez com que o país reduzisse a taxa da incidência da pobreza de 68\%, em 2001, para 36,6\%, em 2009 (INE, 2010), e constituiu um fator positivo para as mulheres, uma vez que são as mais afetadas por esse flagelo (DUCADOS, 2000), bem como proporcionou uma melhoria nas ofertas de emprego. De acordo com as estimativas, a taxa de desemprego passou de 39,8\% em 2002 para 25,2\% em 2006 (BAfD / OCDE, 2008, p. 115) e para 20\% em 2009 (MINPLAN, 2010, p. 23).

No que toca à posição social da mulher, a pressão para que o país implemente medidas e políticas tendo em vista o alcance de uma maior igualdade e equidade entre homens e mulheres - demanda em parte imposta pelos Objetivos de Desenvolvimento do Milénio (ODM) -, conduziu a um aumento dos discursos em torno da sua condição, bem como de algumas medidas que impulsionassem uma maior participação na vida do país. Destacamos aqui o aumento da sua representação em cargos políticos e de decisão. Angola tem, neste momento ${ }^{4}$, no governo 8 mulheres (entre 33 ministros) a ocuparem pastas ministeriais, nomeadamente, Pescas, Indústria, Urbanismo e Habitação, Ambiente, Ciência e Tecnologia, Cultura, Família e Promoção da mulher, Assuntos Parlamentares e 10 secretárias

\footnotetext{
${ }^{4}$ Refere-se a maio de 2016. Em consequência da crise económica que Angola está a atravessar, o presidente de Angola procedeu a uma reestruturação do seu governo durante os primeiros meses do ano de 2016 desde ministros, secretários de estado e governador do Banco Nacional de Angola.
} 
de estado (entre 61 secretários de estado). Porém, são pastas que, se analisarmos bem, estão voltadas para a família e para a educação. As pastas consideradas mais sensíveis, como economia, defesa, administração interna, relações exteriores, petróleo, permanecem sob a liderança de homens. De igual modo, houve um aumento exponencial na representação das mulheres na Assembleia Nacional que, depois das eleições realizadas em 2012, passaram a constituir $36,82 \%$ dos deputados da Assembleia Nacional (IPU, 2014), fazendo com que o país fosse colocado na $10^{a}$ posição mundial com maior representação de mulheres nos órgãos de decisão (PNUD, 2010, p. 36), bem como atingisse a posição 34 entre 136 países em termos de empoderamento políico (WEF, 2013, p. 10).

Verifica-se igualmente um aumento das iniciativas e programas de apoio para melhorar as condições de vida da mulher angolana, camponesa em sua maioria, com destaque para os programas de microcrédito, a realização do Fórum Nacional de Auscultação à Mulher Rural em 2014, que visava mudar o cenário de subalternização da mulher rural, aumentando, desse modo, o seu espaço de afirmação (Ermelinda LIBERATO, 2015), o Fórum Internacional sobre inclusão financeira das mulheres, apenas para destacar alguns exemplos.

\section{A indisfarçável realidade}

A realidade que as mulheres angolanas enfrentam é mais complexa do que os dados aqui apresentados traduzem. De facto, o quotidiano da maioria das mulheres é marcado pela vivência no limiar da pobreza e consequentemente de elaboração de estratégias de sobrevivência. O agravamento dessa situação verifica-se porque o crescimento económico registado não se traduziu em desenvolvimento social, ou seja, na melhoria das condições de vida dos angolanos. Com uma população estimada em 24,4 milhões de habitantes, de acordo com os resultados preliminares do Recenseamento Geral da População e Habitação realizado pelo Instituto Nacional de Estatística (INE) de Angola em 2014 (INE, 2014), o país ocupava, em 2014, a posição 149 com um índice de desenvolvimento humano de 0,526 (baixo desenvolvimento humano) (PNUD, 2014), com uma esperança média de vida de 51,4 anos (PNUD, 2014) e com uma taxa de mortalidade infantil de 167 por cada 1000 nados vivos (WB, 2015). De acordo com o relatório do Banco Mundial Global Economic Prospects for 2015, 43,4\% da população angolana vive com menos de 1,25 dólares por dia (WB, 2015).

De referir ainda que Angola apresenta índices elevados de corrupção. Conforme a Transparency International, Angola ocupava, em 2015, a posição 161 entre 175 países no ranking mundial da corrupção, condição que dificulta o desenvolvimento de qualquer projeto e que afasta todo e qualquer potencial investidor, nacional ou estrangeiro. Segundo o relatório do Banco Internacional para a Reconstrução e Desenvolvimento (IBRD) para 2015, Angola ocupa a posição 181 num total de 189 países. Esse dado significa que é um país muito difícil para se estabelecer um negócio ou empresa. De destacar ainda que o Estado continua a ser o principal empregador, bem como o principal agente económico. Apesar da liberalização, a descentralização ainda é muito tímida, sendo que a presença e o peso do Estado em todos os sectores se mantém, tornando todo e qualquer processo demasiado burocrático, numa falta de dinâmica entre os agentes económicos. Por outro lado, a maioria da população desconhece os seus direitos e a sociedade civil é muito incipiente, sem espaço de atuação e afirmação

A crise económica que atinge o país desde meados de 2014, resultado da queda do preço do petróleo, tem levantado questões preocupantes, sobretudo no tocante à condição da mulher que, uma vez mais, assume a responsabilidade de assegurar a 
sobrevivência da sua família. Uma das principais consequências já registadas prende-se com o aumento do desemprego formal e os atrasos no pagamento dos salários dos funcionários da administração pública, constituídos na sua maioria por mulheres, levandoas a intensificarem outras estratégias de sobrevivência. As preocupações redobram-se quando se trata do meio rural, caracterizado sobretudo por "indicadores que denotam um modo de vida precário, revelado por: estilo de vida simples, à margem das tecnologias e do mundo letrado; recurso a ferramentas tradicionais e obsoletas; atividade produtiva ligada à agricultura de subsistência e pastorícia" (SILVA, 201 1, p. 22). É precisamente no meio rural que se concentra a maioria da população angolana, com destaque para as mulheres e, aqui, "assiste-se à subalternização da mulher e à redução do seu espaço de afirmação" (SILVA, 2011 , p. 28).

A principal constatação que fazemos é que apesar das alterações legislativas e das significativas alterações da posição social da mulher em certas classes sociais, no geral, para a maioria das mulheres angolanas, a sua condição real e posição na sociedade não registou alterações significativas ao longo dos 40 anos de independência. A maioria das mulheres angolanas continua numa condição de desigualdade perante o homem, a viver em condições precárias e a reproduzir essa mesma precariedade para as novas gerações. De acordo com o World Economic Forum de 2015, Angola ocupa a posição 126, entre 145 países, em termos de desigualdade de género. Entre os 31 países africanos que fazem parte da lista, Angola ocupa a posição 26, estando à frente apenas do Benim, de Guiné, da Costa do Marfim, do Mali e do Chade. Esse relatório mostra-nos ainda que Angola apresenta uma performance muito baixa no que toca à educação primária e ao pagamento de serviços pelo mesmo tipo de trabalho realizado pelas mulheres em relação aos homens (WEF, 2015).

Apesar do aumento do número de mulheres em termos de decisores políticos, a realidade do terreno mostra-nos que a maioria das mulheres continua relegada a desempenhar as suas atividades de sobrevivência no sector informal, responsável pelo sustento de mais de $75 \%$ da população angolana (UNCTAD, 2013, p. 39), fazendo de Angola uma "das maiores economias informais do mundo" (UNCTAD, 2013, p. 38), o que nos leva a concordar com Henda Ducados quando afirma que a política e ação do governo angolano pouco tem feito para eliminar alguns dos principais impedimentos para alcançar uma maior igualdade de género (DUCADOS, 2000, p. 5), melhorar as condições de vida e a posição da mulher angolana na sociedade.

Estamos, portanto, muito longe daquilo que foram os ideais traçados há 40 anos, quando da proclamação da independência de Angola, de construir uma Angola igualitária, próspera e fraterna. No entanto, se as "elites dirigentes angolanas faliram em sua tarefa de construção da nação" (SANTOS, 2001, p. 109), os angolanos, no geral, falharam igualmente na construção de uma sociedade no sentido do seu próprio crescimento e desenvolvimento enquanto tal.

\section{Considerações finais}

A comemoração dos 40 anos da independência de Angola constituiu o ponto de partida para a nossa análise, que se desenrolou em três momentos distintos. Primeiramente, traçamos um percurso daquilo que foi, no período pós-independência, a luta das mulheres pela sua afirmação e o reconhecimento da sua posição na sociedade. Esse período, marcado sobretudo pelo desenrolar da guerra civil, fez com que a mulher assumisse um papel de destaque ao garantir a segurança e a sobrevivência da sua família, enquanto os homens estavam a cumprir o dever patriótico de defesa do país. Segue-se um período de 
reacender da esperança, o período de consolidação da paz, de reunião e reconciliação entre os angolanos e a mulher, como pilar da família, assume o papel empreendedor dessa tarefa. É um período de euforia, de expectativas, de sonhos, de ilusão, que rapidamente cede lugar à desilusão e à frustração face a uma realidade indisfarçável, caracterizada pelo crescimento de desigualdade, da exclusão e degradação das condições de vida.

Perante os dados apresentados, constatamos que, ao longo destes 40 anos e apesar de algumas alterações significativas, a condição da mulher angolana continua longe daquilo que foi traçado e defendido quando da proclamação da independência e que constituiu um dos pilares de edificação e construção do país, verificando-se, em muitos casos, com destaque para a mulher rural, um aumento da precariedade da sua condição de vida e degradação da sua condição de mulher. A promessa de emancipação, de transformação das relações sociais, de igualdade entre os cidadãos e de valorização da mulher, bem como dos direitos consagrados na constituição angolana ainda estão, 40 anos depois, por cumprir.

Essa realidade desoladora faz com que o futuro se apresente incerto e pouco otimista. É certo que os motivos para celebração são muito poucos. No entanto, ainda se vai a tempo de mudar de direção e seguir pelo trilho inicialmente traçado, pois continuam presentes todos os motivos para se empreender formas de luta para a edificação das bases em que assentam a independência e a formação do país, mas, sobretudo, para dignificar a mulher como tal e dar a ela o lugar de destaque merecido.

\section{Referências}

ADB (African Development Bank). Angola-perfil do sector privado do país. United Kingdom: African Development Bank, 2012.

BAfD/OCDE (Bank Africaine pour le Developpment/Organization pour la Coopération et le Developpement Économique). Perspetivas Económicas em África. OCDE, 2008.

DUCADOS, Henda. "Género, raça e classe. a feminização da pobreza: a estratificação do sector informal urbano de Luanda". In: SIMPÓSIO O DESAFIO DA DIFERENÇA, Universidade Federal da Bahia, 2000, p. 9-12.

FERREIRA, Manuel Enes; GONÇALVES, Francisco Rocha. "Diplomacia económica e empresas de bandeira. Os casos da Galp e da Unicer em Angola”. Relações Internacionais, n. 24, p. 115-133, 2009.

FORTUNATO, José. Angola: documentos do MPLA. v. 1. Lisboa: Edição do autor, 1977.

HOLNESS, Marga. "Angolan women's congress". African Political Economy, v. 10, n. 27/28, p. 125-129, 1983.

HRW (Human Rights Watch). Transparência e responsabilização em Angola: uma atualização. New York: Human Rights Watch, 2010.

IBRD (International Bank for Reconstruction and Development). Doing Business 2015. Going beyond efficiency. Washington: Bank for Reconstruction and Development, 2014.

INE (Instituto Nacional de Estatística). Recenseamento geral da população e habitação (RGPH) - resultados preliminares. Luanda: INE, 2014.

INE (Instituto Nacional de Estatística). Inquérito integrado sobre o bem-estar da população 2008-2009 (IBEP). Luanda: INE, 2010.

IPU (Inter-Parliamentary Union). Angola, Assembleia nacional, 2014. Disponível em: http:// www.ipu.org/parline-e/reports/2007_A.htm. Acesso em: 30/08/2014.

JIMENEZ, Libertat; LIBERATO, Ermelinda. "A utilização transversal da perspectiva de género nos projetos financiados pelo Instituto Português de Apoio ao Desenvolvimento (IPAD): 
uma questão pendente". Administração Pública e Gestão Social, 7(3), p. 131-137, jul/ set. 2015.

LIBERATO, Ermelinda. "Modelos de desenvolvimento da mulher rural: o Programa de Auscultação à Mulher Rural em Angola". In: XII CONLAB/10 AICSHLP, Lisboa. Atas do XII CONLAB $/ 1^{\circ}$ AICSHLP, Lisboa: FCSH-UNL, 2015, p. 9100-9104.

MENDES, Afonso. A Huíla e Moçâmedes: considerações sobre o trabalho indígena. Lisboa: Junta de Investigações do Ultramar, 1958.

MI (Ministério da Informação). Angola: documentos da independência. Luanda: Ministério da Informação, 1975.

MINPLAN (Ministério do Planeamento). Relatório sobre o desenvolvimento dos Objetivos de Desenvolvimento do Milénio. Luanda: Ministério do Planeamento/PNUD-Angola, 2010.

OECD (Organization for Economic Co-operation and Development). Economic diversification in Africa. A review of selected countries. New York: OECD: OSAA, 2010.

OMA (Organização da Mulher Angolana). Angolan women building the future. Luanda: OMA/Zed Books, 1984.

OMA (Organização da Mulher Angolana). Organização da mulher angolana. Luanda: OMA, 1985.

PNUD. Relatório do Desenvolvimento Humano, 2014. Disponível em http://www.undp.pt. Acesso em: 01/03/2016.

PNUD. Relatório do Desenvolvimento Humano, 2010. Disponível em http://www.undp.pt. Acesso em: 26/01/2012.

PNUD. Os desafios pós-guerra. Luanda: Nações Unidas, 2002.

ROCHA, Alves. As perspetivas de crescimento económico de Angola até 2020. Luanda: CEIC, Working Paper 2. 2014.

ROCHA, Alves. As transformações económicas e estruturais na África Subsariana 2000 2010. Luanda: Mayamba, 2013.

SANTOS, Maciel. "Borracha e tecidos de algodão em Angola (1886-1932). O efeito renda". Porto: WP/CEAUP/\#2012/2, 2012. Disponível em: http://www. africanos.eu/ceaup/uploads/ WP_2012_02.pdf. Acesso em 16/05/2016.

SANTOS, Daniel. "Economia, democracia e justiça em Angola: o efémero e o permanente". Estudos Afro-asiáticos, ano 23, n. 1, p. 100-133, 2001.

SANTOS, Naiole Cohen. Beyond inequalities: women in Angola. Luanda/Harare: ADDRA/ Development Workshop/SARDC, 2000.

SILVA, Eugénio Alves da. "Tradição e identidade de género em Angola: ser mulher no mundo rural". Revista Angolana de Sociologia, n. 8, p. 21-34, 2011.

TUEDTEN, Inge. Angola. Struggle for peace and reconstruction. Colorado: Westview Press, 1997.

UNCTAD (Conferência das Nações Unidas sobre Comércio e Desenvolvimento). Quem se beneficia com a liberalização do comercio em Angola? uma perspetiva de género. Luanda: Nações Unidas, 2013.

URDANG, Stephanie. "Women in national liberation". In HAY, Margaret; STICHIER, Sharon (Ed.). African women south of the sahara. New York: Longman, 1984, p. 140-155.

VALENTE, Maria Idalina. A Situação da Mulher em Angola, 2001. Disponível em: http:// ieham.org/html/docs/A Situacao_Mulher_em_Angola.pdf. Acesso em: 28/08/2014.

VINYALS, Luís. O financiamento público dos setores sociais em Angola. Cascais: Principia, 2002.

WB (World Bank). World economic indicators. Washington: World Bank, 2015. Disponível em: http://data.worldbank.org/news/release-of-world-development-indicators-2015. Acesso em: 30/09/2015. 
WEF (World Economic Forum). The global gender gap report. Geneve: World Economic Forum, 2012

WEF (World Economic Forum). The global competitiveness report 2013-2014. Geneve: World Economic Forum, 2013.

WEF (World Economic Forum). The global gender gap report. Geneve: World Economic Forum, 2015.

[Recebido em 02/05/2016 e aceito para publicação em 18/05/2016]

40 Years of Independence. A Reflection on Angolan Women Condition

Abstract: The celebration of the 40 years of Angola's independence serve as a starting point to do an analysis of the status of women in that country over that period. Because as it is a long period, marked by numerous events that, in one way or another, shaped the country, we divide our analysis into three distinct stages: the post-independence period, characterized by the struggle of women for their statement; the post-war period, marked by economic growth;, and a third period, that especially characterizes the present time that Angolan women are facing. Keywords: Woman; Angola; Independence.

1006 Estudos Feministas, Florianópolis, 24(3): 997-1006, setembro-dezembro/2016 